\title{
Apparent but not real increase in asthma prevalence during the 1990s
}

\author{
R. Barraclough*, G. Devereux\#, D.J. Hendrick*, S.C. Stenton*
}

\begin{abstract}
Apparent but not real increase in asthma prevalence during the 1990s. R. Barraclough, G. Devereux, D.J. Hendrick, S.C. Stenton. (C) ERS Journals Ltd 2002.

ABSTRACT: The authors investigated changes in asthma prevalence and perception of bronchoconstriction over 6 yrs in adults of Newcastle-upon-Tyne.

Postal questionnaires were sent to 6,000 subjects aged 20-44 yrs in 1992-1993 and 1998-1999. Random samples of 600 responders had assessments of atopy, airway responsiveness, and their ability to perceive methacholine-induced bronchoconstriction. The prevalences of asthmatic symptoms, physician-diagnosis, and medication use increased by an average of $4.4 \%$, particularly in subjects aged $<30$ yrs $(8.7$ versus 2.7$)$. Atopy prevalence increased from $25 \%$ to $31 \%$ but atopics and nonatopics had similar mean changes in questionnaire data $(5.2$ versus 3.4$)$. The probability of a positive methacholine test decreased as did the mean methacholine dose/response slope $(\mathbf{0 . 0 0 5 2 7}$ to $\mathbf{0 . 0 0 3 7 9}$ ), indicating lower levels of airway responsiveness. This can be largely explained by an increase in use of inhaled corticosteroids $(5.0-9.3 \%)$. The proportion of subjects perceiving bronchoconstriction during methacholine tests increased from 63 to $77 \%$.
\end{abstract}

The authors conclude that current changes in asthma epidemiology in adults may result from increased awareness of symptoms (and/or an increased willingness to report them), and from an increased willingness of physicians to make the diagnosis and prescribe treatment, not from increased disease prevalence.

Eur Respir J 2002; 20: 826-833.
*Dept of Respiratory Medicine, Royal Victoria Infirmary, University of Newcastle-upon-Tyne, Newcastle-uponTyne, and "Dept of Environmental and Occupational Medicine, Aberdeen Royal Infirmary, Aberdeen University, Aberdeen, UK.

Correspondence: S.C. Stenton, Dept of Respiratory Medicine, Royal Victoria Infirmary, University of Newcastleupon-Tyne, Queen Victoria Road, Newcastle-upon-Tyne, NE1 4LP, UK. Fax: 441912275224

E-mail: s.c.stenton@ncl.ac.uk

Keywords: Airway responsiveness, asthma, atopy, epidemiology

Received: January 312002

Accepted after revision: April 242002

This study was supported by a grant from the National Asthma Campaign.
Asthma prevalence appears to have increased dramatically in industrially developed countries over the last two decades as judged by hospital admission rates, diagnoses, use of medication, and certified deaths. An increase in disease prevalence has been supported by a number of studies in which the same population has been surveyed more than once at intervals of $\leqslant 25$ yrs [1-4]. Observed rates of change for those affected within UK populations have been $>6 \%$ per annum for $8-13$-yr-old children $[1,2], 7 \%$ per annum for university entrants [3], and $8 \%$ per annum for 12-yr-old children [4]. These findings were based on questionnaire responses, and so may have been influenced by increased awareness of asthmatic symptoms and an increased likelihood of reporting them. There is a possible source of confusion in expressing the magnitude of change in terms of percentage; if prevalence itself is quantified as a percentage (as in the present study) and increases from, for example, $4.5-4.8$, the net change of 0.3 represents a $7 \%$ increase in the number of affected subjects.

Few studies have included objective features of asthma severity or prevalence, such as airway responsiveness measurements, and no clear picture has emerged from those that have. BurR et al. [4] reported a greater than two-fold increase in "current asthma" amongst schoolchildren between 1973 and 1988, but there was only a $15 \%$ increase in the proportion who showed a bronchoconstrictor response to exercise (decrement in peak expiratory flow of $>15 \%$ ). By contrast, PEAT et al. [5] showed that an 87\% increase in "current asthma" amongst 8-10-yr-old children between 1982 and 1992 was paralleled by an $83 \%$ increase in the prevalence of airway hyperresponsiveness to histamine [5]. However, the type of nebuliser used for the inhalation challenge tests was changed over the period of their study (with a probable change in aerosol output) and this might have confounded the result [6]. The same group showed a relatively modest $21 \%$ increase in "current asthma" between 1981 and 1990 in 18-55 yr olds, and found that the prevalence of airway hyperresponsiveness fell over the period of the study [7]. These discrepancies raise the possibility that recent increases in symptom reporting, physician diagnoses, and medication (which involve countries as widely separated as Australia, Finland, and the USA [5, 8, 9]) do not reflect a true increase in the pathophysiological abnormalities of asthma. They led a recent reviewer to conclude that the evidence for an increase in asthma prevalence is weak and that further studies of defined populations using objective data are necessary [10].

The current authors have conducted surveys of the adult population of Newcastle-upon-Tyne in the north east of England in 1992-1993 and 1998-1999 using the same methodology and equipment. In these 
surveys, objective measurements of spirometry, airway responsiveness, and atopy were made in addition to questionnaire assessments of symptoms, physician diagnoses, and medication. The perception of bronchoconstriction reported by participants undergoing methacholine tests was also assessed.

\section{Methods}

The study followed closely, but not exactly, the design of the European Community Respiratory Health Survey (ECRHS) [11]. An initial survey was carried out in 1992-1993 and a repeat survey in 1998-1999. On each occasion a postal questionnaire was sent to 6,000 adult residents of Newcastle-uponTyne aged 20-44 yrs, randomly selected from the Health Authority register and stratified equally by age and sex. Each subject received up to three mailings of a short questionnaire comprising nine items about asthmatic symptoms and treatment, and a further item related to hay fever (table 1). All mailings were carried out between July and September. To assess response bias attributable to an incorrect address, a random sample of nonresponders was investigated by comparing details on the Health Authority register with those on the Electoral Roll.

A random sample of responders was then invited to attend the laboratory for an interviewer-administered questionnaire, measurements of height and weight, skin-prick tests with six common aeroallergens, spirometric tests, and a methacholine-challenge test. The aim was to recruit 600 subjects for these laboratory studies of each survey. The methods were the same in the two surveys and have been published in detail elsewhere $[12,13]$. All laboratory studies took place between October and April to avoid the pollen season.

Methacholine was administered by nebuliser in doubling cumulative doses over the range 3.125$6,400 \mu \mathrm{g}$. Airway responsiveness was expressed both as the dose/response slope (DRS) and as the dose of methacholine provoking a $20 \%$ fall in forced expiratory volume in one second (FEV1, PD20) [14]. Using this methodology, PD20 values $<200 \mu \mathrm{g}$ are usually associated with active asthma, values $200-1,000 \mu \mathrm{g}$ are sometimes associated with active asthma, and values $>1,000 \mu \mathrm{g}$ are seldom associated with active asthma [12, 15]. The precision of the method is described fully elsewhere [13].

To assess perception of bronchoconstriction, all subjects were asked: whether they were aware of any abnormal respiratory sensation at the point of maximal bronchoconstriction at the end of the methacholine test, even if the decrement in FEV1 was of a negligible degree; whether the sensation could be described as wheeze, chest tightness, or breathlessness; and whether it had ever been experienced before [16]. Local ethics approval was obtained and all subjects gave written informed consent.

The data from the two surveys were pooled and Chi-squared tests, unpaired t-tests, and stepwise multiple linear and logistic regression techniques were used to identify predictors of participation in the study, symptoms, and airway responsiveness.

Table 1. - Response prevalences from postal and laboratory questionnaires

\begin{tabular}{|c|c|c|c|c|c|}
\hline Item & Questionnaire & $1992-1993$ & 1998-1999 & Change & p-value \\
\hline \multirow[t]{2}{*}{ Responses $n$} & Postal & 3047 & 2803 & & \\
\hline & Laboratory & 626 & 615 & & \\
\hline \multirow[t]{2}{*}{ Wheezing ever } & Postal & 42.6 & 45.8 & 3.2 & 0.014 \\
\hline & Laboratory & 43.0 & 54.3 & 11.3 & $<0.001$ \\
\hline Wheezing in last year & Laboratory & 29.8 & 36.4 & 6.6 & 0.013 \\
\hline Ever wheeze no cold & Postal & 29.6 & 33.7 & 4.1 & 0.001 \\
\hline Ever short of breath and wheeze & Postal & 22.8 & 28.0 & 5.2 & $<0.001$ \\
\hline \multirow{2}{*}{ Woken wheezing in last year } & Postal & 9.0 & 12.4 & 3.4 & $<0.001$ \\
\hline & Laboratory & 12.7 & 17.7 & 5.0 & 0.01 \\
\hline \multirow[t]{2}{*}{ Woken breathless in last year } & Postal & 10.0 & 13.6 & 3.6 & $<0.001$ \\
\hline & Laboratory & 8.2 & 8.7 & 0.5 & NS \\
\hline \multirow{2}{*}{ Woken with chest tightness in last year } & Postal & 19.7 & 23.9 & 4.2 & $<0.001$ \\
\hline & Laboratory & 12.2 & 13.5 & 1.3 & NS \\
\hline \multirow{2}{*}{ Woken coughing in last year } & Postal & 30.9 & 37.8 & 6.9 & $<0.001$ \\
\hline & Laboratory & 24.5 & 30.4 & 5.9 & 0.02 \\
\hline \multirow[t]{2}{*}{ Asthma attack in last year } & Postal & 5.4 & 8.8 & 3.4 & $<0.001$ \\
\hline & Laboratory & 7.5 & 10.2 & 2.7 & NS \\
\hline \multirow[t]{2}{*}{ Mean change in symptom prevalence } & Postal & & & 4.3 & \\
\hline & Laboratory & & & 4.8 & \\
\hline \multirow[t]{2}{*}{ Current asthma medication } & Postal & 7.5 & 12.8 & 5.3 & $<0.001$ \\
\hline & Laboratory & 8.3 & 10.7 & 2.4 & NS \\
\hline Asthma ever diagnosed by doctor & Laboratory & 12.7 & 16.9 & 4.2 & 0.03 \\
\hline \multirow[t]{2}{*}{ Overall mean change } & Postal & & & 4.4 & \\
\hline & Laboratory & & & 4.4 & \\
\hline \multirow[t]{2}{*}{ Hay fever } & Postal & 28.3 & 34.4 & 6.1 & $<0.001$ \\
\hline & Laboratory & 26.1 & 37.8 & 11.7 & $<0.001$ \\
\hline
\end{tabular}

Data are present as \% unless otherwise stated. NS: nonsignificant. 


\section{Results}

\section{Response rates}

The response rates to the postal questionnaire were similar in the two surveys, with 3,047 valid replies in $1992-1993(51 \%)$ and 2,803 in 1998-1999 (47\%). The adjusted response rate, which took account of concordance between the Health Authority register and the Electoral Roll, fell from $84 \%$ in $1992-1993$ to $69 \%$ in 1998-1999. The response rate was lower in the younger age groups in both surveys, and this effect was more marked in 1998-1999, resulting in an increase in the mean age of the population from $32.2-34.0$ yrs $(\mathrm{p}<0.001)$. Females were more likely to respond $(55.1 \%$ of responders in 1992-1993 and $58.1 \%$ in $1998-1999)$, and the change over 6 yrs was significant $(\mathrm{p}=0.02)$.

The response rate amongst those invited to participate in the laboratory studies was 35\% in 1992-1993 and $28 \%$ in 1998-1999, giving 626 and 615 participants, respectively. They were slightly older in 19981999 (35.0 versus 33.2 yrs, $\mathrm{p}<0.0001$ ) reflecting the increased age of the responders to the postal questionnaire, but similar proportions were current smokers $(28 \%$ in $1992-1993$ and $27.5 \%$ in $1998-1999, p=0.8)$ or exsmokers $(25.5 \%$ in $1992-1993$ and $21 \%$ in 1998-1999, $\mathrm{p}=0.2$ ), and total cigarette consumption was similar (6.3 pack-yrs in 1993-1994 and 5.4 in $1998-1999, p=0.2)$. In both surveys, increasing age and response to an early mailing of the postal questionnaire were the strongest predictors of participation in

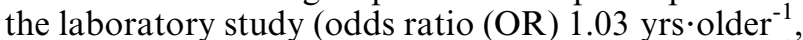
95\% confidence interval (CI) 1.02-1.04; 0.64 mailing $^{-1}$, $95 \%$ CI $0.57-0.72$ ). A positive response to any of the nine respiratory items on the postal questionnaire was also a significant predictor of laboratory participation (OR for any item $1.18,95 \%$ CI $1.04-1.35$ ), as was hay fever (OR 1.23, 95\% CI 1.07-1.41).

\section{Questionnaires}

The postal and laboratory questionnaires identified substantial increases from 1992-1993 to 1998-1999 in the prevalences of asthmatic symptoms, physician diagnosis, and use of medication (table 1). The prevalences of symptoms increased by a mean of $4.3 \%$ on the postal questionnaire and $4.8 \%$ on the laboratory questionnaire. There were very similar prevalence increases in physician-diagnosed asthma (4.2\%) and the use of medication $(4.8 \%$, weighted mean from both questionnaires), giving an average overall change of $4.4 \%$ over the 6 yrs. The use of inhaled corticosteroids rose from $5.0 \%$ to $9.3 \%(\mathrm{p}=0.003)$, and inhaled $\beta$-agonists from $10.5 \%$ to $14.1 \%$ ( $\mathrm{p}=0.054$ ). No dosage information was obtained. In subjects with a physician-diagnosed asthma, inhaled corticosteroid use increased from $37.2 \%$ to $52.9 \% \quad(p=0.035)$, but there was no change in $\beta$-agonist use ( $68 \%$ versus $64 \%$, $\mathrm{p}=0.6$ ).

The increases were more marked in participants aged $<30$ yrs (overall 8.7\%) compared with those who were older $(2.7 \%)$. For the laboratory study, in which

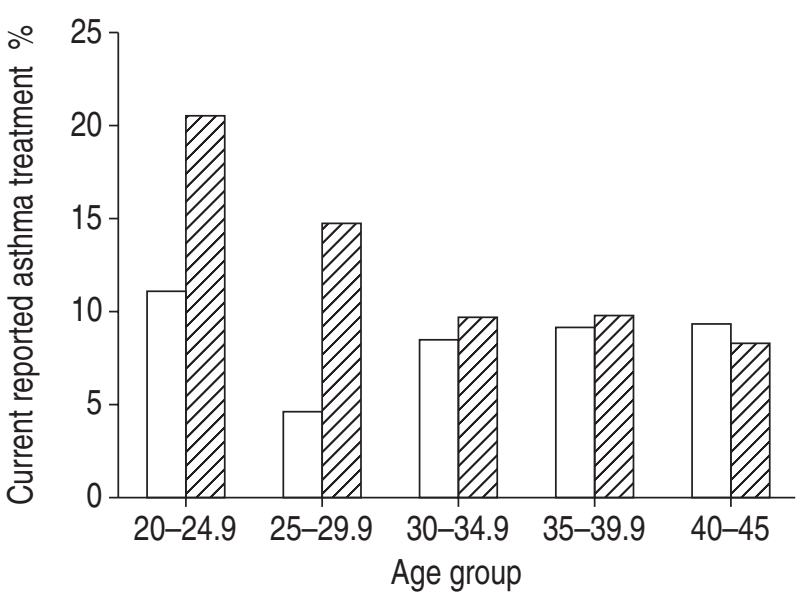

Fig. 1.- Percentages of laboratory populations reporting current

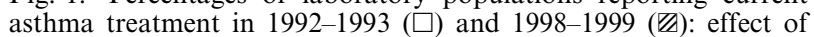
age.

corresponding measurements of airway responsiveness were obtained, the increases in positive questionnaire responses from these younger participants were especially striking for "asthma attacks in last year" (7.2\%, $\mathrm{p}=0.025)$, "physician-diagnosed asthma" $(13.7 \%, \mathrm{p}<0.0001)$, and "current medication" (fig. 1).

\section{Airway responsiveness}

Methacholine tests were carried out in 591 subjects (302 males and 289 females) in 1992-1993, and 580 (303 males and 277 females) in 1998-1999. The remaining 68 participants in the laboratory studies (from both surveys) either declined or were considered unsuitable because of pregnancy, cardiac disease, epilepsy or baseline FEV $1<60 \%$ of the predicted value.

The means for the baseline measurements of FEV1 exceeded $100 \%$ pred and did not differ significantly between the two surveys (table 2). The baseline FEV1 is not, therefore, likely to have differently influenced PD20 measurements between the two surveys. A positive methacholine test (i.e. PD20 <6,400 $\mu \mathrm{g}$ ) was obtained from $37.2 \%$ of subjects in 1992-1993

Table 2.-Lung function, airway responsiveness levels, and atopy

\begin{tabular}{lcll}
\hline & $1992-1993$ & $1998-1999$ & p-value \\
\hline $\begin{array}{l}\text { Mean FEV1 \% } \\
\text { pred (SEM) }\end{array}$ & $102.9(0.59)$ & $104.3(0.58)$ & 0.09 \\
PD20 <6400 $\mu \mathrm{g}$ & 37.2 & 31.6 & 0.041 \\
PD20 <1000 $\mu \mathrm{g}$ & 22.5 & 16.6 & 0.01 \\
PD20 <200 $\mu \mathrm{g}$ & 9.1 & 7.6 & 0.338 \\
Geometric mean DRS & 0.00527 & 0.00379 & 0.004 \\
Atopic $^{\#}$ & 24.8 & 31.1 & 0.015 \\
\hline
\end{tabular}

Data are present as \% unless otherwise stated. FEV1: forced expiratory volume in one second; PD20: provocative concentration causing a $20 \%$ fall in FEV1; DRS: dose/ response slope. \#: at least one positive allergen skin test (wheal $\geqslant 4 \mathrm{~mm}$ greater than that of saline control) [10]. 


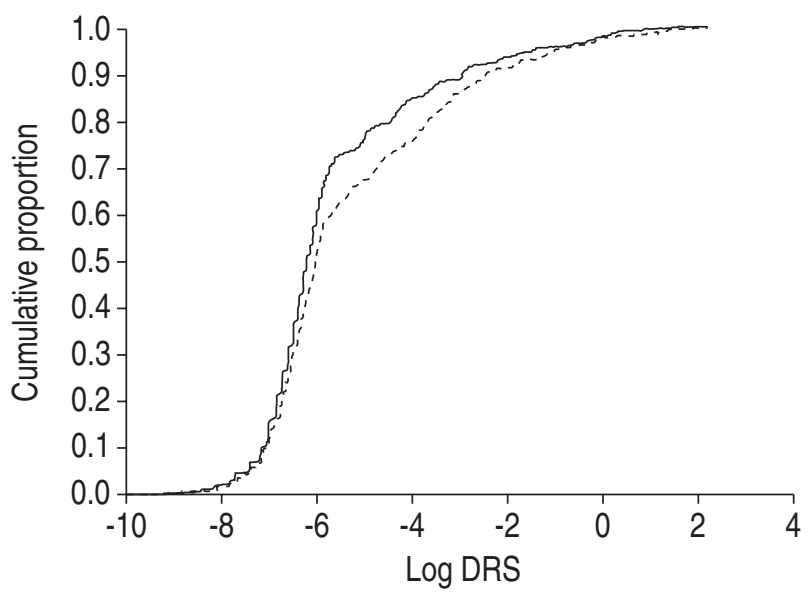

Fig. 2.-Distribution of airway responsiveness (dose/response slope (DRS)) in the population samples of 1992-1993 (-) and 19981999 (---). Geometric mean DRS 1992-1993=0.00525, 1998$1999=0.00377, \mathrm{p}=0.002$.

compared with $31.6 \%$ in $1998-1999$, indicating that airway hyperresponsiveness was less prevalent in the later survey (table 2 and fig. 2). The geometric mean DRS lessened in parallel from 0.00527 to 0.00379 $(p=0.004)$. Multiple regression analyses showed that this association with survey year was of borderline statistical significance after adjusting for the effects of sex, smoking, and baseline FEV1 expressed as a percentage of the predicted value (table 3 ). The OR for a positive methacholine test in 1998-1999 compared with 1992-1993 was 0.77 (95\% CI 0.58-1.01). Similar results were obtained for the analysis of $\mathrm{PD} 20<1,000 \mu \mathrm{g} \quad(\mathrm{OR} \quad 0.64,95 \%$ CI $0.49-0.90)$, PD20<200 $\mu \mathrm{g}$ (OR 0.79, 95\% CI 0.49-1.26), and log DRS ( $\mathrm{t}=-3.17, \mathrm{p}=0.002)$.

For the younger participants, aged $<30 \mathrm{yrs}$, the prevalence of airway responsiveness at a level consistent with active asthma (PD20<1,000 $\mu \mathrm{g}$ ) fell from $26.9 \%$ to $22.7 \%$, despite the increases in positive responses to the questionnaires.

Table 3. - Logistic regression analysis of airway responsiveness: provocative concentration causing a $20 \%$ fall in forced expiratory volume in one second (FEV 1 , PD20) $<6400 \mu \mathrm{g}$ methacholine

\begin{tabular}{lccc}
\hline & Odds ratio & $\begin{array}{c}95 \% \\
\text { Confidence } \\
\text { interval }\end{array}$ & p-value \\
\hline $\begin{array}{c}\text { Atopy per } \\
\text { positive allergen }\end{array}$ & 2.05 & $1.71-2.46$ & $<0.001$ \\
$\begin{array}{c}\text { Sex female } \\
\text { versus male }\end{array}$ & 2.43 & $1.84-3.22$ & $<0.001$ \\
$\begin{array}{c}\text { Smoking status } \\
\text { yes versus no }\end{array}$ & 2.26 & $1.68-3.03$ & $<0.001$ \\
$\begin{array}{c}\text { Baseline FEV1 per \% } \\
\text { less than pred }\end{array}$ & 0.94 & $0.93-0.95$ & $<0.001$ \\
$\begin{array}{c}\text { Survey 1998-1999 } \\
\text { versus 1992-1993 }\end{array}$ & 0.77 & $0.58-1.01$ & $\mathrm{NS}$ \\
\hline
\end{tabular}

NS: nonsignificant; pred: predicted.
Table 4. - Predictors of perception of bronchoconstriction during methacholine tests

\begin{tabular}{|c|c|c|}
\hline & $\begin{array}{l}\text { Odds } \\
\text { ratio }\end{array}$ & $\begin{array}{l}95 \% \text { Confidence } \\
\text { interval }\end{array}$ \\
\hline $\begin{array}{l}\text { Year of study } 1998-1999 \\
\text { versus } 1992-1993\end{array}$ & 2.78 & $2.04-3.78$ \\
\hline Age per year & 0.97 & $0.94-0.99$ \\
\hline Sex female versus male & 1.55 & $1.14-2.10$ \\
\hline $\begin{array}{l}\text { Degree of bronchoconstriction } \\
\text { per } \% \text { fall of FEV } 1\end{array}$ & 1.09 & $1.06-1.13$ \\
\hline PD20 per band ${ }^{\#}$ & 0.64 & $0.47-0.89$ \\
\hline Atopy yes versus no & 1.77 & $1.21-2.59$ \\
\hline
\end{tabular}

Data drawn from both surveys. FEV1: forced expiratory volume in one second; PD20: provocative concentration causing a $20 \%$ fall in FEV1. ${ }^{\#}:<200 \mu \mathrm{g}, 200-1000 \mu \mathrm{g}, 1001-$ $6400 \mu \mathrm{g},>6400 \mu \mathrm{g} ;{ }^{\uparrow}$ : at least one positive allergen skin test (wheal $\geqslant 4 \mathrm{~mm}$ greater than that of saline control) [10].

\section{Perception of bronchoconstriction}

Younger age, female sex, the presence of symptoms on the laboratory questionnaire, the degree of bronchoconstriction during the methacholine test, a lower band of PD20 measurement $(<200 \mu \mathrm{g}, 200-1,000 \mu \mathrm{g}$, $1,001-6,400 \mu \mathrm{g}, \quad>6,400 \mu \mathrm{g}$ methacholine), atopy, and involvement in the 1998-1999 survey were all predictors of the ability to perceive (and report) methacholine-induced bronchoconstriction when the results from both surveys were combined (table 4). In $1992-1993,62.5 \%$ of subjects reported the development of an abnormal respiratory sensation at the end of the methacholine test compared with $77.2 \%$ in 1998-1999 ( $\mathrm{p}<0.001$, fig. 3). The associations with younger age, symptoms, and the degree of methacholine-induced bronchoconstriction were apparent within both the 1992-1993 and the 19981999 populations separately, but the association with sex was only significant in the 1992-1993 population. The association with atopy was of borderline statistical significance in 1992-1993 (OR 1.75, 95\% CI 0.99-3.08) but was clearly significant in 1998-1999

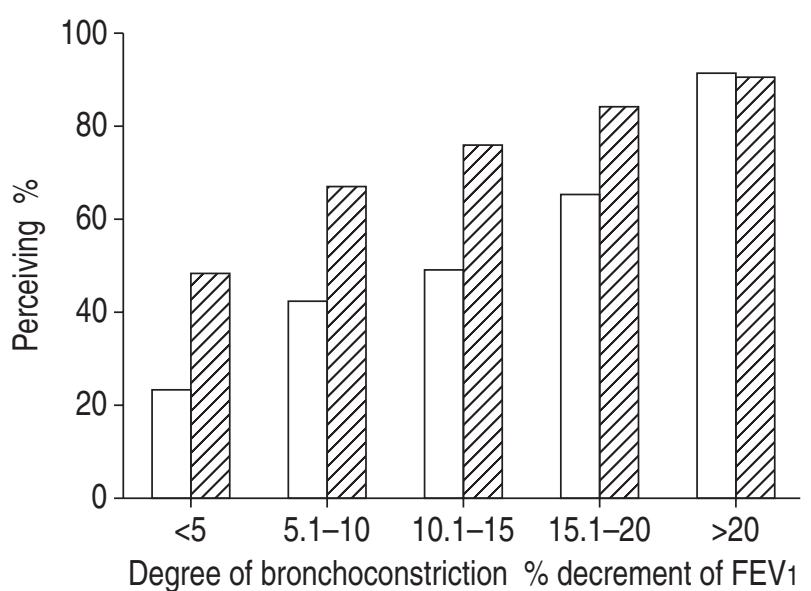

Fig. 3.-Perception of bronchoconstriction during methacholine test in 1992-1993 ( $\square$ ) and 1998-1999 (ש). FEV1: forced expiratory volume in one second. 
(OR 1.99, 95\% CI 1.15-3.43). There were no differences between the two surveys in the terms used to describe the respiratory sensation induced by bronchoconstriction, or in the proportion of subjects who reported having experienced this previously.

\section{Atopy}

The proportion of subjects with at least one positive allergen skin test (defined as a mean wheal diameter $\geqslant 4 \mathrm{~mm}$ greater than the saline control [10]) increased between 1992-1993 and 1998-1999 from 24.8\% to $31.1 \%$. This was mostly attributable to an increase in responses to Timothy grass pollen, with a nonsignificant increase in the responses to Dermatophygoides pteronyssinus. The significant predictors of atopy were younger age (OR $0.95 \mathrm{yr}^{-1}, 95 \%$ CI $\left.0.93-0.97\right)$, male sex (OR 1.7, 95\% CI 1.31-2.20), involvement in the 1998-1999 survey (OR 1.56 for 1998-1999, 95\% CI 1.20-2.03) and nonsmoking (OR 0.67 for smokers, $95 \%$ CI $0.50-0.90)$. Symptom prevalences increased almost as much in nonatopics as in atopics $(3.8 \%$ versus $5.4 \%$, table 5 ), and the predictive value of atopy for physician-diagnosed asthma fell slightly between the two surveys (OR 4.3, 95\% CI 2.6-6.9 in 1992-1993 and OR 3.7, 95\% CI 2.2-6.1 in 1998-1999). Both

Table 5.-Absolute changes in prevalence from the laboratory study between 1992-1993 and 1998-1999 for symptoms, physician diagnosis and treatment, by atopic status

Nonatopic Atopic

\begin{tabular}{lcc}
\hline Wheezing ever & 10.4 & 9.0 \\
Wheezing in last year & 4.7 & 8.7 \\
Woken wheezing in last year & 3.5 & 6.6 \\
Woken breathless in last year & 0 & 1.5 \\
Woken with chest tightness in last year & -0.8 & 5.2 \\
Woken coughing in last year & 7.0 & 3.0 \\
Asthma attack in last year & 1.7 & 3.9 \\
Mean change in prevalence rates & 3.8 & 5.4 \\
Current asthma medication & 1.4 & 3.1 \\
Asthma ever diagnosed by doctor & 2.5 & 5.7 \\
Overall mean increase & 3.4 & 5.2 \\
Hay fever ever & 6.9 & 13.9
\end{tabular}

Data are presented \%. ${ }^{*}$ : participant numbers, nonatopic versus atopic: 1992-1993, 471 versus 155; 1998-1999, 424 versus 191. nonatopics and atopics showed decreases in the levels of airway responsiveness, with that in the atopics being no less than that in the nonatopics (table 6). For the logistic regressions that assessed the predictors of symptoms and airway responsiveness, the year of survey (i.e. change from 1992-1993 to 1998-1999) did not show an interaction with atopy (or sex, or smoking). This indicates that atopic status (such as sex and smoking) was not a significant determinant for the changes that were observed.

\section{Discussion}

The current authors have identified significant increases relevant to asthma in the prevalences of symptoms, physician diagnosis, and use of medication in the young adult population of Newcastle-uponTyne between 1992-1993 and 1998-1999. The rates of increase are substantial and equivalent to a $\sim 5 \%$ increase per annum in the number of subjects affected, but they are similar to those reported in other studies in which the same population has undergone repeated investigation [1-5]. The rates of increase are more striking in subjects aged $<30$ yrs. A recent study of general practice consultation rates suggested that the UK asthma "epidemic" might have peaked around 1993 [17], but the findings of that study could be explained by organisational changes or by changes in treatment. Other data from UK general practice suggest an increase in asthma prevalence between 1994 and 1996, similar to that found in the current study [18].

The increases in asthmatic symptoms in the current study were paralleled by an increase in the prevalence of atopy, as judged by skin-prick test results and questionnaire reporting of hay fever (table 1). The greatest effect was on the skin test response to Timothy grass pollen, which might be the most labile from year to year due to variations in the extent of pollen exposure. However, similar though smaller changes were seen with $D$. pteronyssinus and cat, which suggests a real increase in atopy similar to that found in other studies [1, 2, 19]. As with the asthmatic symptoms, there was a tendency for the increase in atopy to be more marked in the younger subjects, after adjusting for sex and smoking.

Although asthma and atopy were associated in both 1992-1993 and 1998-1999 surveys, the increases in asthmatic symptoms were not much greater in the atopic than the nonatopic groups, and the proportion

Table 6. - Ventilatory function and airway responsiveness in 1992-1993 and 1998-1999, by atopic status

\begin{tabular}{|c|c|c|c|c|c|c|}
\hline & \multicolumn{3}{|c|}{ Nonatopic } & \multicolumn{3}{|c|}{ Atopic } \\
\hline & 1992-1993 & 1998-1999 & p-value & 1992-1993 & 1998-1999 & $\mathrm{p}$-value \\
\hline Mean FEV1 \% pred (SEM) & $103.4(0.69)$ & $104.9(0.72)$ & 0.13 & $101.6(1.2)$ & $103.1(0.99)$ & 0.32 \\
\hline $\mathrm{PD} 20<6400 \mu \mathrm{g}$ & 30.6 & 26.5 & 0.187 & 57.5 & 43.2 & 0.01 \\
\hline $\mathrm{PD}_{20}<1000 \mu \mathrm{g}$ & 16.4 & 10.6 & 0.014 & 41.1 & 30.7 & 0.052 \\
\hline PD20 $<200 \mu \mathrm{g}$ & 5.8 & 3.5 & 0.115 & 19.2 & 17.1 & 0.62 \\
\hline Geometric mean DRS & 0.00377 & 0.00272 & 0.004 & 0.0145 & 0.00832 & 0.038 \\
\hline
\end{tabular}

Data are presented as \% unless otherwise stated. FEV1: forced expiratory volume in one second; PD20: provocative concentration causing a $20 \%$ fall in FEV1; DRS: dose/response slope. 
of physician-diagnosed asthma that could be attributed to atopy fell slightly from $42 \%$ to $38 \%$ over the period of the study. Other investigations have identified a similar lack of association between changes in asthma and changes in atopy. For example, the prevalence of atopy among Leipzig schoolchildren increased from 19 to $27 \%$ between 1991 and 1996 but there was no change in the prevalence of apparent asthma or airway responsiveness over the same period [19]. Conversely, Australian schoolchildren showed a more than two-fold increase in asthma prevalence over the 1980s with no significant changes in atopy prevalence $[5,7]$. Asthma and atopy are not as closely associated as is commonly supposed, even amongst children [20], and these epidemiological studies suggest that factors other than increased atopy or increased exposure to common environmental aeroallergens have been making important contributions to the changing epidemiology of asthma.

UPTON et al. [21] recently reported that increased diagnostic awareness could have been entirely responsible for a 2.5-fold increased asthma prevalence in nonatopic subjects between 1972 and 1996. They found no evidence that a similar bias influenced the diagnosis of atopic asthma, but the extent to which the increases in estimates of asthma prevalence generally are related to increased awareness and increased willingness to make the diagnosis is uncertain. The present authors' failure to identify increases in airway responsiveness in parallel with the increased prevalence of symptoms supports the possibility that these factors have exerted an important influence.

The current findings are not likely to have been due to a measurement artefact. The dosimeter and nebulisers were identical in the two surveys, the dosimeter was calibrated for aerosol output before each survey using an ion tracer method, and there was considerable overlap in the research personnel [22]. Furthermore, the increase in symptom prevalence noted from the questionnaires in 1998-1999 was accompanied by an increased, not decreased, reported awareness of bronchoconstriction in association with the methacholine tests. The increase was seen only with decrements of FEV $1<20 \%$ and was most marked at the lowest level of bronchoconstriction. Thus, reported perception of FEV1 decrements $<5 \%$ increased in prevalence from 22.9 to $55.1 \%$, while for decrements of $16-20 \%$ the increase was from 74.7 to $86.5 \%$ (fig. 3). Decrements in FEV1 of $<5 \%$ indicate levels of airway responsiveness well below those conventionally associated with asthma, and they suggest that symptoms are now being reported after relatively trivial changes in airway calibre.

The prevalence of inhaled corticosteroid use increased from 5.0 to $9.3 \%$ over the period of the current study. Such medication can be expected to increase mean PD20 values $3-4$ fold $[23,24]$, and is therefore likely to be the chief explanation for the observed decrease in the measured mean level of airway responsiveness in 1998-1999. In an attempt to adjust for these differences in corticosteroid use, the data was re-analysed after lowering the PD20s of those using inhaled corticosteroids by a factor of four. Thus, the levels of airway responsiveness that would have been present at the times of both surveys had it not been for corticosteroid use were estimated. There were then similar proportions of the population in the PD20 $<200 \mu$ g category in 1992-1993 (9.6\%) and 1998-1999 $(9.1 \%)$. The corresponding figures for the PD20 category $<1,000 \mu \mathrm{g}$ were $22.8 \%$ in $1992-1993$ and $17.4 \%$ in $1998-1999$. Similar outcomes were observed when the atopics and nonatopics were analysed separately. These analyses strengthen the current authors' beliefs that the diminished level of airway responsiveness in 1998-1999 can be largely explained by the increased use of inhaled corticosteroids, and that this increase in corticosteroid use did not mask an actual increase in airway responsiveness. The findings are consistent with other recent studies. PEAT and colleagues $[5,7]$ noted an increase in asthma symptoms but a nonsignificant decrease in the distribution of airway responsiveness in young adults in Australia, and, in a case-controlled study, Richter et al. [25] showed almost a doubling of asthma diagnoses in Hamburg from 1990-1991 to 1995-1996 but a slight decrease in airway responsiveness [25].

The overall importance of selection biases to the present findings is difficult to estimate. They are potentially important, as the presence of respiratory symptoms is a recognised determinant of participation in such studies [26]. To the present authors' knowledge, the current study is the first repeat survey of a population following the ECRHS template and so the repeatability of the methodology is unknown. The response rates in these surveys were within the range reported by centres participating in the ECRHS, but they were low and the response rate in the second survey was lower than the first. The method of DRANE [27] was used to estimate overall symptom prevalences in the population. This assumes a linear relationship between symptom prevalence and the probability of responding to a postal questionnaire, and it extrapolates results from a series of mailings to estimate the prevalence in nonresponders. It did not lead to any reduction in the estimates of the prevalence increases in asthma symptoms, physician diagnosis, or treatment. There were also no systematic differences in response to the postal questionnaire between those who did and did not take part in the subsequent laboratory studies. The critical point is that recruitment bias is not likely to explain the discrepant findings of increased symptoms yet decreased airway responsiveness.

VAN SCHYACK et al. [28] demonstrated that individuals with poor perception of bronchoconstriction are less likely than others to seek medical attention. The converse is also likely to be true, and the increased perception of bronchoconstriction reported in the current population over $6 \mathrm{yrs}$ in association with the methacholine tests is likely to have contributed to the increased prevalences of asthmatic symptoms and physician-diagnosed asthma. Little is known about the mechanisms that underlie the perception of bronchoconstriction and the explanation for the change in this population is unclear. Bronchoconstriction may not have been the true cause in all the subjects responding positively, since measured decrements in FEV1 were of trivial degree in some. It is 
likely, however, that there were more subtle physiological changes, perhaps at the small airway level. The authors have consequently used the term "bronchoconstriction" somewhat loosely to indicate the maximum effect generated by the administration of methacholine.

Females, younger subjects, and atopics are recognised to have an increased ability to perceive bronchoconstriction [29] and these relationships were apparent in the present study. The increase in the prevalence of atopy was not, however, a major factor because this increased ability to perceive methacholine-induced bronchoconstriction was seen almost equally amongst both atopics and nonatopics, and there was no interaction between atopic status and the influence of the second survey of 1998-1999. Treatment with inhaled corticosteroids has been reported to increase the perception of bronchoconstriction [30] but this is unlikely to have had an effect as substantial as was seen in the present study population. Psychological factors can influence the perception of most sensory stimuli and it is likely that increased education and awareness of asthma among the current population was responsible. About $15 \%$ of the young adult population have intermediate levels of airway responsiveness (PD20 between 200 and $1,000 \mu \mathrm{g}$ using the current authors' techniques) but in only $\sim 20 \%$ of these have physician-diagnosed asthma [16]. These $20 \%$ show few, if any, differences from the $80 \%$ majority in terms of airway physiology, so changes in the ability to perceive bronchoconstriction (and report it) have the potential to make a substantial contribution to estimates of asthma prevalence.

The current authors believe that the results presented here are consistent with the hypothesis that the current rise in asthma symptom recognition, diagnosis, and treatment in adults is largely a consequence of better education, increased awareness of symptoms, and/or increased readiness to report them, and an increased willingness of physicians to make the diagnosis and initiate treatment. No objective evidence of any increase in the prevalence or severity of the pathophysiological features of asthma was found.

\section{References}

1. Ninan T, Russell G. Respiratory symptoms and atopy in Aberdeen schoolchildren: evidence from two surveys 25 years apart. BMJ 1992; 304: 873-875.

2. Omran M, Russell G. Continuing increase in respiratory symptoms in Aberdeen schoolchildren. BMJ 1996; 312: 34.

3. Bruce I, Harland R, Mcbride N, Macmahon J. Trends in the prevalence of asthma and dyspnoea in first year university students, 1972-89. Q J Med 1993; 86: 425430.

4. Burr M, Butland B, King S, Vaughan Williams E. Changes in asthma prevalence: two surveys 15 years apart. Arch Dis Child 1989; 64: 1452-1456.

5. Peat J, Van der Berg R, Green W, Mellis C, Leeder S, Woolcock A. Changing prevalence of asthma in Australian children. BMJ 1994; 308: 1591-1596.

6. Hartley-Sharp C, Booth H, Johns D, Walters E. Differences in aerosol output and airways responsiveness between the de Vilbiss 40 and 45 hand held nebulisers. Thorax 1995; 50: 635-638.

7. Peat J, Haby M, Spijker J, Berry G, Woolcock AJ. Prevalence of asthma in adults in Busselton, Western Australia. BMJ 1992; 305: 1326-1329.

8. Reijula K, Haahtela T, Klaukka T, Rantanen J. Incidence of occupational asthma and persistent asthma in young adults has increased in Finland. Chest 1996; 110: 3-5.

9. Vollmer WM, Osborne ML, Buist AS. 20-year trends in the prevalence of asthma and chronic airflow obstruction in an HMO. Am J Respir Crit Care Med 1998; 157: 1079-1084.

10. Magnus P, Jaakkola J. Secular trend in the occurrence of asthma among children and young adults: critical appraisal of repeated cross sectional surveys. BMJ 1997; 314: 1795-1799.

11. Burney P, Luczynska C, Chinn S, Jarvis D. The European Community Respiratory Health Survey. Eur Respir J 1994; 7: 954-960.

12. Devereux G, Ayatollahi T, Ward R, et al. Airway responsiveness, asthma, and air pollution in two contrasting districts of northern England. Thorax 1996; 51: 169-174.

13. Beach JR, Young CL, Avery AJ, et al. Measurement of airway responsiveness to methacholine: relative importance of the precision of drug delivery and the method of assessing response. Thorax 1993; 48 239-243.

14. O'Connor G, Sparrow D, Taylor D, Segal M, Weiss S. Analysis of dose-response curves to methacholine. Am Rev Respir Dis 1987; 136: 1412-1417.

15. Stenton SC, Beach JR, Avery AJ, Hendrick DJ. The value of questionnaires and spirometry in asthma surveillance programmes in the workplace. Oсcupational Med 1993; 43: 203-206.

16. Devereux G, Hendrick DJ, Stenton SC. Asthmatic symptoms, airway hyperresponsiveness and the perception of bronchoconstriction. Eur Respir J 1998; 12: 1089-1093.

17. Fleming DM, Sunderland R, Cross KW, Ross AM. Declining incidence of episodes of asthma: a study of trends in new episodes presenting to general practitioners in the period 1989-98. Thorax 2000; 55: 657661.

18. Lung and Asthma Information Agency. Prevalence of asthma treated in general practice. Factsheet 99/1. London, Department of Public Health Sciences, 1991.

19. von Mutius E, Weiland SK, Fritzsch C, Duhme H, Keil U. Increasing prevalence of hay fever and atopy among children in Leipzig. Lancet 1998; 351: 862868.

20. Pearce N, Pekkanen J, Beasley R. How much asthma is really attributable to atopy? Thorax 1999; 54 $268-272$.

21. Upton MN, McConnachie A, McSharry C, et al. Intergenerational 20 year trends in the prevalence of asthma and hay fever in adults: the Midspan family study surveys of parents and offspring. BMJ 2000; 321: 88-92.

22. Dennis JH, Stenton SC, Beach JR, Avery AJ, Walters EH, Hendrick DJ. Jet and ultrasonic nebuliser output: use of a new method for direct measurement of aerosol output. Thorax 1990; 45: 728-732.

23. Barnes PJ. Effects of corticosteroids on airway hyperresponsivness. Am Rev Respir Dis 1990; 141: $70-76$. 
24. Convery RP, Leitch DN, Bromly C, Ward RJ, Bartlett G, Hendrick DJ. Effect of inhaled fluticasone proprionate on airway responsiveness in treatment-naïve individuals - a lesser benefit in females. Eur Respir $J$ 2000; 15: 19-24.

25. Richter K, Heinrich J, Jorres RA, Magnussen H, Wichman HE. Trends in bronchial hyperresponsiveness, respiratory symptoms and lung function among adults: West and East Germany. Respir Med 2000; 94: 668-677.

26. Chinn S, Burney P, Jarvis D, Luczynska C. Variation in bronchial responsiveness in the European Community Respiratory Health Survey (ECHRS). Eur Respir J 1997; 10: 2495-2501.
27. Drane JW. Imputing non responses to mail-back questionnaires. Am J Epidemiol 1991; 134: 908-912.

28. Van Schayck CP, van der Heijden FMMA, van den Boom G, Tirimanna PRS, van Herwaarden CLA. Underdiagnosis of asthma: is the doctor or the patient to blame? Thorax 2000; 55: 562-565.

29. Brand PLP, Jijcken B, Schouten JP, Koeter GH, Weiss ST, Postma DS. Perception of airway obstruction in a random population sample. Am Rev Respir Dis 1992; 146: 396-401.

30. Boulet LP, Turcotte H, Cartier A, Milot J, Cote J, Malo JL. Influence of beclomethasone and salmeterol on the perception of methacholine-induced bronchoconstriction. Chest 1998; 114: 373-379. 